\title{
Statistical study on great geomagnetic storms during solar cycle $23^{*}$
}

\author{
Qi Li ${ }^{1, \star} \quad$ Yufen Gao ${ }^{1}$ Peiyu Zhu ${ }^{2}$ Huaran Chen ${ }^{1}$ Xiuling Zhang ${ }^{3}$ \\ ${ }^{1}$ Institute of Geophysics, China Earthquake Administration, Beijing 100081, China \\ ${ }^{2}$ Chongming Observatory, Earthquake Administration of Shanghai Municipality, Shanghai 202164, China \\ ${ }^{3}$ Beijing Observatory, Institute of Geophysics, China Earthquake Administration, Beijing 100095, China
}

\begin{abstract}
Characteristics of great geomagnetic storms during solar cycle 23 were statistically investigated. Firstly, we focused on the uniqueness of solar cycle 23 by analyzing both the great storm number and sunspot number from 1957 to 2008. It was found that the relationship between the sunspot number and great storm number weakened as the activity of the storms strengthened. There was no obvious relationship between the annual sunspot number and great storm number with Dst $\leq-300 \mathrm{nT}$. Secondly, we studied the relationship between the peak Dst and peak Bz in detail. It was found that the condition $\mathrm{Bz} \leq-10 \mathrm{nT}$ is not necessary for storms with Dst $\leq-100 \mathrm{nT}$, but seems necessary for storms with Dst $\leq-150 \mathrm{nT}$. The duration for Bz $\leq-10 \mathrm{nT}$ has no direct relationship with the giant storm. The correlation coefficient between the Dst peak and Bz peak for the 89 storms studied is 0.81 . After removing the effect of solar wind dynamic pressure on the Dst peak, we obtained a better correlation coefficient of 0.86 . We also found the difference between the Dst peak and the corrected Dst peak was proportional to the Dst peak.
\end{abstract}

Key words: geomagnetic storms; solar cycle 23; sunspot number; 4.5 solar cycles; peak Dst and peak $\mathrm{Bz}$

CLC number: P318. $2^{+} 2$ Document code: A

\section{Introduction}

It is well known that magnetic activity observed on the ground depends on solar activity. Chapman and Bartels (1940) found that geomagnetic activity is correlated with the sunspot number, so the occurrence of magnetic storms has the same period of the solar cycle.

A magnetic storm is a global geomagnetic field disturbance characterized by a distinct decrease in the horizontal component of the magnetic field at mid- and low-latitudes. It is generally accepted that the source of the magnetic disturbance is a westward ring current circling the Earth in the equatorial plane. The strength of a magnetic storm is usually estimated using the Dst index, which is derived from hourly values of the horizontal component of the geomagnetic field recorded at

\footnotetext{
* Received 12 May 2011; accepted in revised form 28 July 2011; published 10 August 2011.

† Corresponding author. e-mail: darcyli@163.com

(c) The Seismological Society of China and Springer-Verlag Berlin Heidelberg 2011
}

four low-latitude stations. Gonzalez et al. (1994) defined the storms with $-30 \mathrm{nT} \leq \mathrm{Dst} \leq-50 \mathrm{nT}$ as weak storms, those with $-50 \mathrm{nT} \leq \mathrm{Dst} \leq-100 \mathrm{nT}$ as moderate storms and those with Dst $\geq-100 \mathrm{nT}$ as great or intensive magnetic storms, and the classification has been extensively adopted.

The input energy of geomagnetic storms comes from the Sun, and the energy is transferred into the Earth's magnetosphere by streams of solar wind. The energy from solar wind is injected into the magnetosphere only in the case when the interplanetary magnetic field (IMF) has a significant component parallel to the terrestrial magnetic dipole; i.e., an approximately negative (southward) Bz component of the IMF (Russell et al., 1974; Perreault and Akasofu, 1978; Tsurutani and Gonzalez, 1997; Gonzalez et al., 2007; Echer et al., $2008 \mathrm{a}, \mathrm{b})$. The mechanism for energy transfer between the solar wind and magnetosphere is the magnetic reconnection between the IMF and the Earth's magnetic field (Dungey, 1961), and the energy transfer efficiency is of the order of $10 \%$ during intensive magnetic 
storms (Gonzalez et al., 1989). Gonzalez et al. (2011a) reviewed the interplanetary causes of intensive geomagnetic storms, and pointed out that the most common interplanetary structures leading to the development of intensive storms were magnetic clouds, sheath fields, sheath fields followed by a magnetic cloud and corotating interaction regions at the leading fronts of high speed streams. Gonzalez and Tsurutani (1987) found that intensive storms with peak Dst $\leq-100 \mathrm{nT}$ are primarily caused by large fields with $\mathrm{Bz} \leq-10 \mathrm{nT}$ and a duration longer than three hours. Kane and Echer (2007) examined the evolutions of severe geomagnetic storms (Dst $<200 \mathrm{nT}$ ) during solar cycle 23, and noticed that the phase delay between the maximum of interplanetary negative $\mathrm{Bz}$ and the maximum of negative Dst varied in a very wide range from storm to storm. Zhang et al. (2011) indicated that the product of solar wind density and the south component of IMF determine the development of the main phase of a geomagnetic storm.

Solar cycle 23 started in April 1996 with a sunspot number of 8.0 and reached its peak in March 2000 with a maximum sunspot number of 120.8. Afterward, the sunspot number for each year decreased toward a minimum. The maximum sunspot number of solar cycle 23 was lower than those of solar cycles 19, 21 and 22. However, cycle 23 was very active, and there were five giant magnetic storms with Dst $\leq-300 \mathrm{nT}$ in the declining years 2001, 2003 and 2004. Furthermore, three of these giant storms occurred within one month. In addition, there are more satellite data for the Sun and IMF in solar cycle 23 than that in previous solar cycles, which is favorable for research work on space weather. Solar cycle 23 is very interesting and has been the subject of much research (Dal et al., 2004; Gopalswamy et al., 2005; Gonzalez and Echer, 2005; Gonzalez et al., 2007).

In this paper, we statistically investigated characteristics of great geomagnetic storms during solar cycle 23. In section 2, we focused on the uniqueness of solar cycle 23 by analyzing both the great storm number and sunspot number from 1957 to 2008, which covers 4.5 solar cycles from the latter part of solar cycle 19 to solar cycle 23. In section 3 , we investigated the relationship between the peak Dst and peak Bz in detail. We believe that these studies are important for space weather forecasting.

\section{The uniqueness of solar cycle 23}

\subsection{Data preparation}

The one-hour Dst index obtained from the World Data Center for Geomagnetism, Kyoto was used to characterize the intensity of a magnetic storm. The Dst index has been published since 1957, so we studied storms latter than that year. The Dst index is available in its final form for the period from 1957 to 2003. It should be noted that the Dst index after 2003 is provisional, and that the Dst index after 2006 was given in real time when this work was undertaken, and hence the final index could be a little different. The international sunspot number was obtained from the National Geophysical Data Center of the National Oceanic and Atmospheric Administration. All magnetic storms with Dst $\leq-100 \mathrm{nT}$ from 1957 to 2008 were used.

\subsection{Comparison between solar cycle 23 and other cycles}

There were 402 great storms with Dst $\leq-100 \mathrm{nT}$ from 1957 to 2008, with an average of 7.7 storms per year; the maximum number of such storms was 20 , both in 1960 and 1989. There were 71 great storms with Dst $\leq-200 \mathrm{nT}$ during the same period, with an average of 1.4 storms per year; the maximum number of such storms was 7 in 1957. There were 22 giant storms with Dst $\leq-300 \mathrm{nT}$, with an average of 0.4 storms per year; the maximum number of such storms was three in 1957, 1958, 1960 and 2003. The years 1957, 1958 and 1960 were in solar cycle 19 and only the year 2003 was in solar cycle 23.

Table 1 shows the annual occurrence rate of great magnetic storms of different intensities. The table shows that the annual occurrence rate in cycle 23 was only lower than that in cycle 19 for storms with Dst $\leq-200 \mathrm{nT}$ and Dst $\leq-300 \mathrm{nT}$.

Table 1 Annual occurrence rate of great magnetic storms with different intensities

\begin{tabular}{ccccccc}
\hline \multirow{2}{*}{ Intensity of storms } & \multicolumn{9}{c}{ Annual occurrence rate } \\
\cline { 2 - 7 } & All storms & Cycle 19 & Cycle 20 & Cycle 21 & Cycle 22 & Cycle 23 \\
\hline Dst $\leq-100 \mathrm{nT}$ & 7.7 & 10.9 & 4.4 & 7.9 & 9.5 & 7.3 \\
Dst $\leq-200 \mathrm{nT}$ & 1.4 & 2.5 & 0.75 & 1.3 & 1.1 & 1.5 \\
Dst $\leq-300 \mathrm{nT}$ & 0.4 & 1.25 & 0.08 & 0.3 & 0.2 & 0.5 \\
\hline
\end{tabular}


Figure 1 shows the ratio of the storm number to the maximum annual number of sunspots for each solar cycle. It can be seen that the ratio is the greatest in cycle 23 for storms with Dst $\leq-100 \mathrm{nT}$ or Dst $\leq-200 \mathrm{nT}$.

There were 22 giant storms with Dst $\leq-300 \mathrm{nT}$ from 1957 to 2008. Table 2 shows the occurrence date and times of these storms according to Dst. Among them, 10 storms appeared in cycle 19 and six storms appeared in cycle 23. Table 2 indicates that four of the 10 most intense giant storms appeared in cycle 23 .
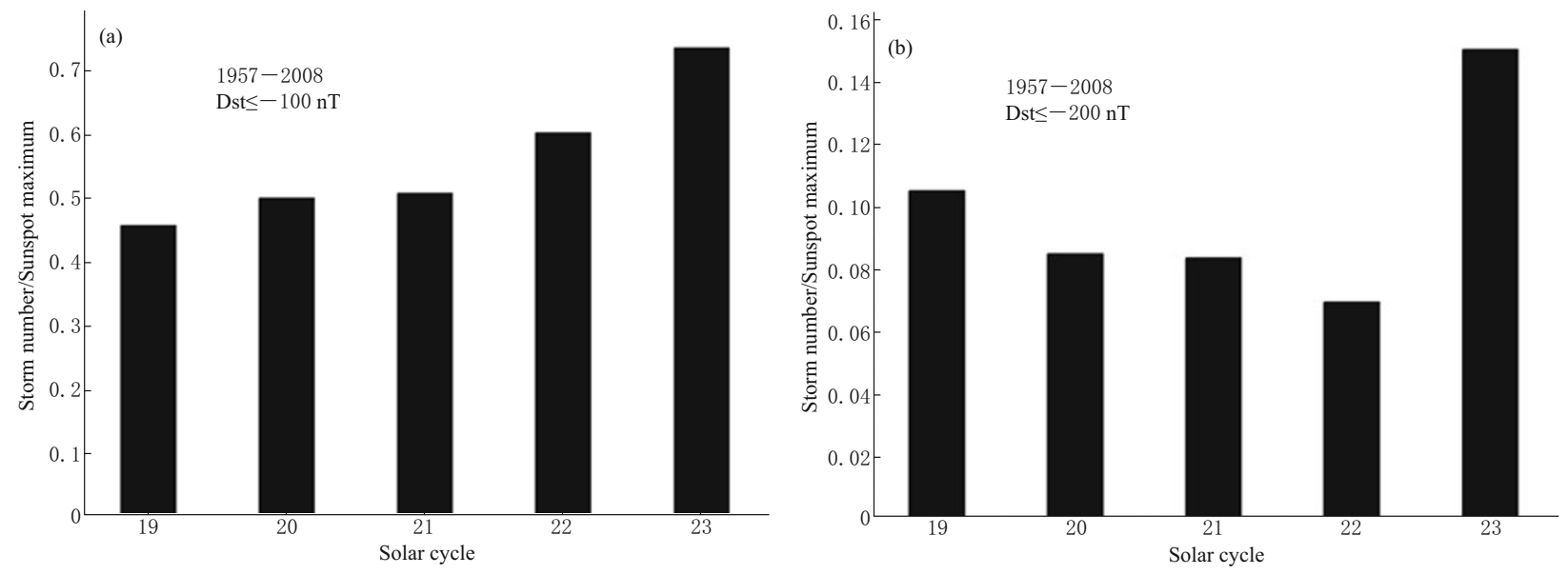

Figure 1 Ratio of the storm number to the maximum annual number of sunspots in each solar cycle for magnetic storms with Dst $\leq-100 \mathrm{nT}$ (a) and for magnetic storms with Dst $\leq-200 \mathrm{nT}$ (b).

Table 2 List of giant storms with Dst $\leq-300$ nT from 1957 to 2008

\begin{tabular}{|c|c|c|c|c|c|c|c|}
\hline Order & $\begin{array}{c}\text { Date } \\
\text { a-mo-d }\end{array}$ & $\begin{array}{l}\text { Time } \\
\text { h:min }\end{array}$ & Dst & Order & $\begin{array}{c}\text { Date } \\
\text { a-mo-d }\end{array}$ & $\begin{array}{l}\text { Time } \\
\text { h:min }\end{array}$ & Dst \\
\hline 1 & 1989-03-13 & $01: 28$ & -589 & 12 & $1960-11-12$ & $13: 49$ & -339 \\
\hline 2 & 1959-07-15 & 08:03 & -429 & 13 & 1958-07-08 & $07: 49$ & -330 \\
\hline 3 & 1957-09-13 & $00: 46$ & -427 & 14 & $1960-03-31$ & $04-$ & -327 \\
\hline 4 & $1958-02-11$ & $01: 27$ & -426 & 15 & $1960-04-30$ & 01:30 & -325 \\
\hline 5 & $2003-11-20$ & 08:02 & -422 & 16 & $1982-07-13$ & $16: 18$ & -325 \\
\hline 6 & $1967-05-24$ & $17: 29$ & -387 & 17 & 1957-09-04 & $13: 00$ & -324 \\
\hline 7 & 2001-03-19 & $11: 13$ & -387 & 18 & 1981-04-11 & $05-$ & -311 \\
\hline 8 & $2003-10-30$ & $16: 36$ & -383 & 19 & 1986-02-06 & $13: 12$ & -307 \\
\hline 9 & 2004-11-07 & $18: 28$ & -373 & 20 & 1957-09-22 & $13: 45$ & -303 \\
\hline 10 & 2003-10-29 & $06: 11$ & -353 & 21 & 1958-09-03 & 08:41 & -302 \\
\hline 11 & 1991-11-08 & $06: 47$ & -354 & 22 & $2000-07-15$ & $14: 37$ & -301 \\
\hline
\end{tabular}

2.3 Relationship between the sunspot number and the great storm number from 1957 to 2008

Figure 2 shows the relationship between the annual sunspot numbers and great storm numbers from 1957 to 2008. The correlation coefficients for great storm numbers with Dst $\leq-100 \mathrm{nT}$ and Dst $\leq-200 \mathrm{nT}$ are 0.79 and 0.64 , respectively. It is obvious that there is no relationship between the annual sunspot number and great storm number with Dst $\leq-300 \mathrm{nT}$ in the figure.

Figure 3 shows the annual sunspot numbers and the numbers of great storms with different intensities to make their relationship clearer. The curve indicates the distribution of sunspot numbers, and the columns lists the numbers of great storms with Dst $\leq-100 \mathrm{nT}$,
Dst $\leq-200$ nT, Dst $\leq-300$ nT, Dst $\leq-400$ nT and Dst $\leq-500 \mathrm{nT}$, respectively. The sunspot number curve shows five obvious periods from solar cycle 19 to solar cycle 23. The year of the cycle maximum and corresponding annual mean sunspot number are 1957, 190.2; 1968, 105.9; 1979, 155.4; 1989, 157.6 and 2000, 119.6, respectively. The relation between the sunspot number and great storm number weakened as the intensity of magnetic storms strengthened. For example, the annual sunspot number of the solar cycle 23 maximum is only larger than that of the solar cycle 20 maximum, but both the number of intense storms with Dst $\leq-200 \mathrm{nT}$ and the number with Dst $\leq-300 \mathrm{nT}$ in solar cycle 23 are only less than the numbers for solar cycle 19, which was the most active solar cycle among the five studied. 

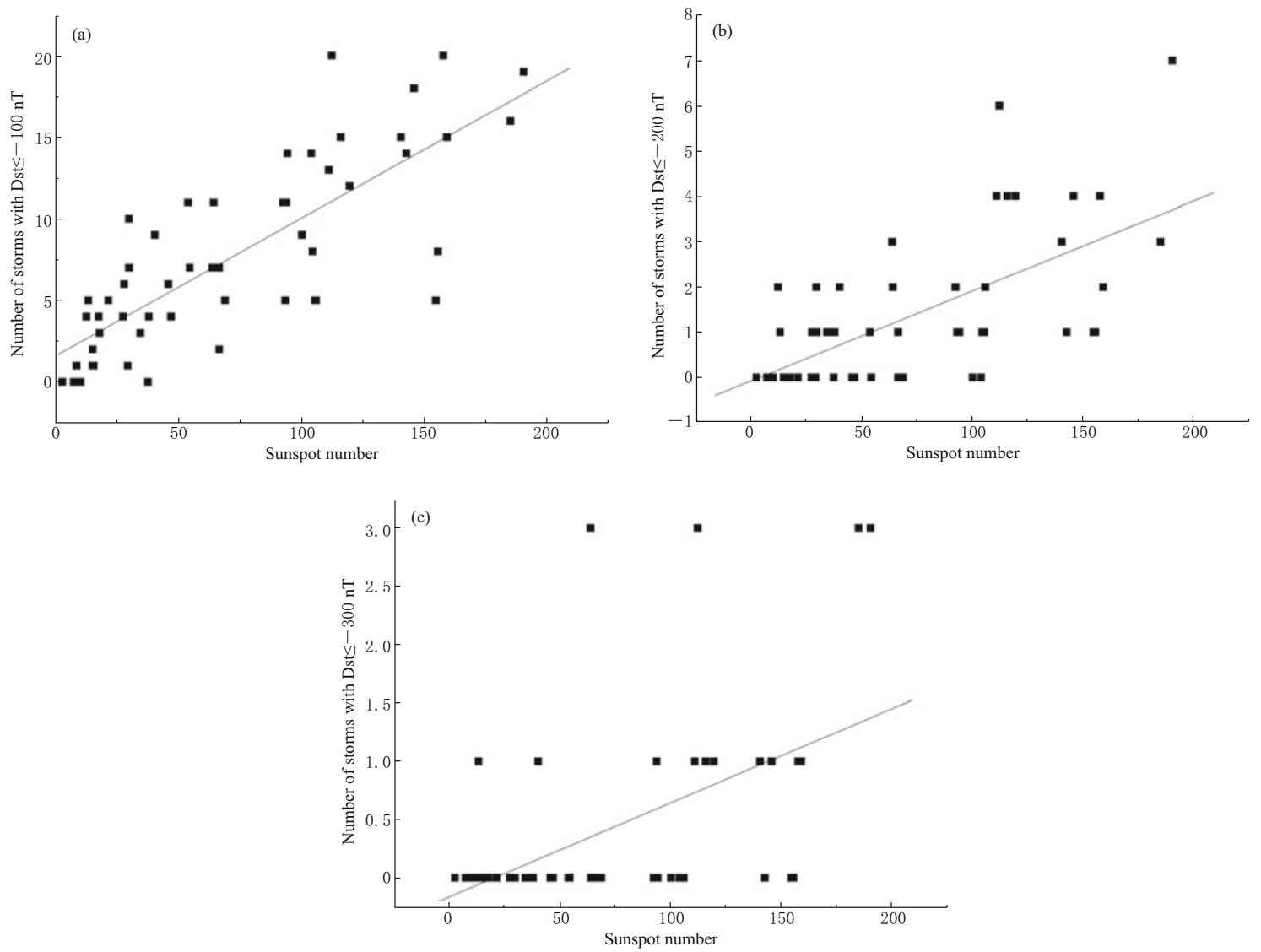

Figure 2 Relationship between the annual sunspot number and great storm number from 1957 to 2008. (a) For magnetic storms with Dst $\leq-100 \mathrm{nT}$, (b) for magnetic storms with Dst $\leq-200 \mathrm{nT}$, (c) for magnetic storms with Dst $\leq-300 \mathrm{nT}$.

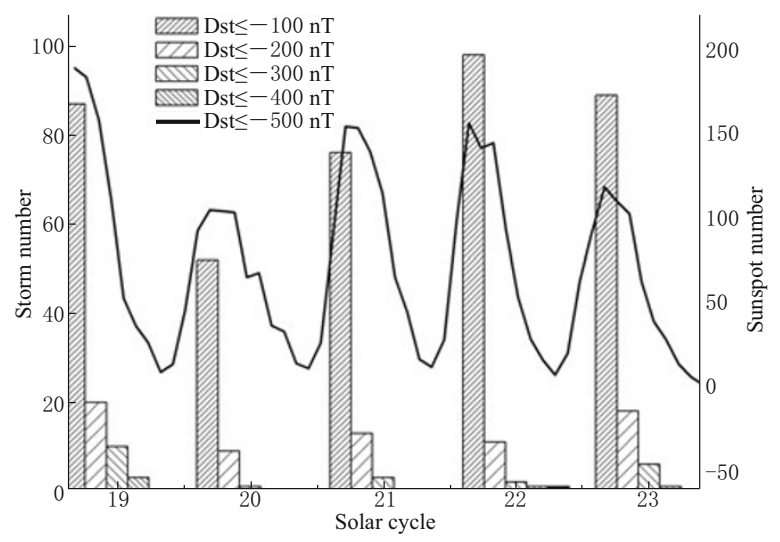

Figure 3 Annual sunspot numbers and great storm numbers for different intensities.

\section{Relationship between the peak $\mathrm{Bz}$ and the peak Dst in solar cy- cle 23}

\subsection{Analysis method}

One-hour data of the IMF parameters were obtained from the Goddard Space Flight Center at the Na- tional Aeronautics and Space Administration and had a shift of $\sim 200$ Re $(\sim 0.01$ AU) upstream of the Earth (1 AU). Therefore, we do not need to consider the propagation time between Lagrangian point $L_{1}$, where the Atmospheric Chemistry Experiment satellite is orbiting, and the Earth. We selected great storms with Dst $\leq-100$ $\mathrm{nT}$ in solar cycle 23 from 1996 to 2008 . There were 89 magnetic storms with Dst $\leq-100 \mathrm{nT}$ during the period, including 18 storms with Dst $\leq-200 \mathrm{nT}$, six storms with Dst $\leq-300 \mathrm{nT}$ and one storm with Dst $\leq-400 \mathrm{nT}$. The annual and monthly distributions of these storms are similar to those reported by Zhang et al. (2007). Comparing with the storms of cycle 23 used by Zhang et al. (2007), two magnetic storms appearing in April and December of 2006 are added in this paper, and the storm appearing on August 7, 1998 is excluded because we believe it cannot be considered to be an individual storm according to the magnetic field variation on that day. Therefore, the magnetic storm number in this paper is one more than that in the work of Zhang et al. (2007).

Figure 4 shows $\mathrm{Bz}$ and Dst profiles during inten- 
sive magnetic storms from April 17 to April 19, 2001 as an example of the analysis. The Dst and $\mathrm{Bz}$ peaks are identified by the labels Dst ${ }_{\text {peak }}$ and $\mathrm{Bz}_{\text {peak }}$. There are two dotted vertical lines passing through the Dst and $\mathrm{Bz}$ peaks in the figure to illustrate the delay time between peaks $\Delta T_{1}$. A dotted horizontal line for $\mathrm{Bz}=-10 \mathrm{nT}$ is also shown, and the duration for which $\mathrm{Bz} \leq-10 \mathrm{nT}$ is denoted $\Delta T_{2}$. If $\mathrm{Bz}$ is still lower than $-10 \mathrm{nT}$ after the Dst peak or Bz peak, then we define $\Delta T_{2}$ as being until $\mathrm{Bz}_{\text {peak }}$ when $\mathrm{Bz}_{\text {peak }}$ lags behind Dst $t_{\text {peak }}$, and being until Dst peak $_{\text {otherwise. }}$

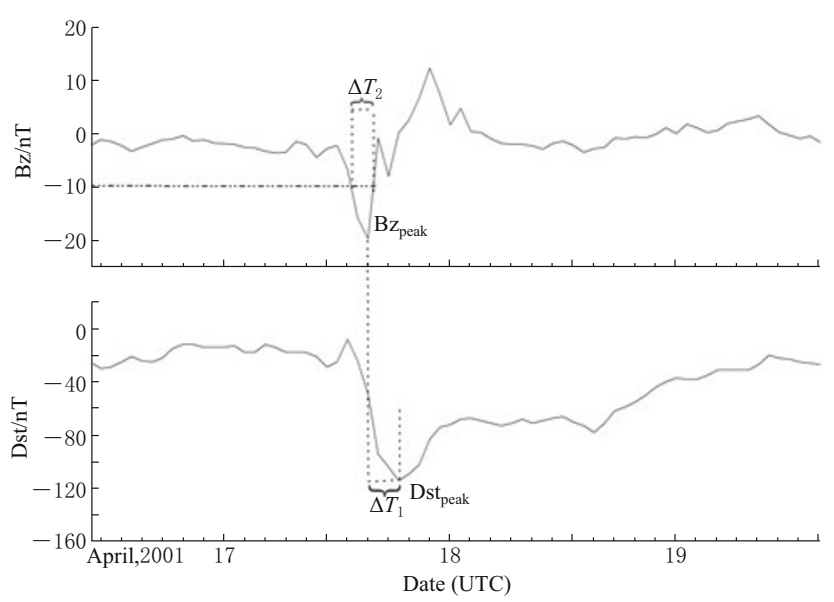

Figure 4 Bz and Dst profiles during intense magnetic storms from April 17 to April 19, 2001. The peak values of $\mathrm{Bz}$ and $\mathrm{Dst}$ are denoted $\mathrm{Bz}_{\text {peak }}$ and $\mathrm{Dst}_{\text {peak }}$, the delay between the Dst and Bz peaks is denoted $\Delta T_{1}$, and the duration with $\mathrm{Bz} \leq-10 \mathrm{nT}$ is denoted $\Delta T_{2}$.

To remove the effect of solar wind dynamic pressure on Dst peak $_{\text {, we corrected Dst }}$ peak as Dst ${ }_{\text {peak }}^{*}$ according to Burton et al. (1975).

$$
\mathrm{Dst}_{\text {peak }}^{*}=\operatorname{Dst}_{\text {peak }}-b \cdot P^{1 / 2}+C,
$$

Where $P$ is the solar wind dynamic pressure and $b$ and $C$ are constants. We set $b=8.74 \mathrm{nT}(\mathrm{nPa})^{-1 / 2}$ and $C=11.54$ nT (Turner et al., 2001).

This procedure was performed for each storm. For those storms with multiple peaks, only the highest peak was considered. If there were two continuous Dst peaks of the same magnitude, we chose the one with the higher Dst ${ }_{\text {peak }}^{*}$ as the final Dst peak. Considering that the magnetosphere/ring current response time to $\mathrm{Bz}$ was one hour (Akasofu, 1981), the Dst value was corrected for this time; i.e., the Dst curve was shifted one hour back in time.

\subsection{Results}

Table 3 shows the averages and standard deviations of storm parameters for the 89 storms sorted by the storm activity. The number of storms $\left(N_{\mathrm{s}}\right)$, Dst peak (Dst peak $), \mathrm{Bz}$ peak $\left(\mathrm{Bz}_{\text {peak }}\right)$, delay between the peaks of $\mathrm{Bz}$ and Dst $\left(\Delta T_{1}\right)$, duration of $\mathrm{Bz} \leq-10$ $\mathrm{nT}\left(\Delta T_{2}\right)$ and difference $\Delta\left(\right.$ Dst $_{\text {peak }}-$ Dst $\left._{\text {peak }}^{*}\right)$ between the Dst peak and the corrected Dst peak are listed. It was found that the $\mathrm{Bz}$ peak and $\Delta\left(\right.$ Dst $_{\text {peak }}-$ Dst $\left._{\text {peak }}^{*}\right)$ had close relationships with the Dst peak; i.e., the $\mathrm{Bz}$ peak and $\Delta\left(\right.$ Dst $_{\text {peak }}-$ Dst $\left._{\text {peak }}^{*}\right)$ increased as the Dst peak increased. However, no clear relationship was found between $\Delta T_{1}$ or $\Delta T_{2}$ and the Dst peak.

Table 3 shows that the average and standard deviation of the peak $\mathrm{Bz}$ for the 89 storms studied were -18.34 and $10.31 \mathrm{nT}$, respectively. The distribution of the storm number as a function of the Bz peak is shown in Figure 5. It was found that more than half (62.9\%) of the $\mathrm{Bz}$ peaks were between $-10 \mathrm{nT}$ and $-20 \mathrm{nT}$ and $91 \%$ were between 0 and $-30 \mathrm{nT}$.

Table 3 Average storm parameters for 89 Storms (1996-2008) sorted by the storm activity

\begin{tabular}{ccccccc}
\hline \multirow{2}{*}{ Activity of storms } & \multirow{2}{*}{$N_{\mathrm{s}}$} & \multicolumn{5}{c}{ Average \pm Standard deviation } \\
\cline { 3 - 7 } & & Dst $_{\text {peak }}$ & $\mathrm{Bz}_{\text {peak }}$ & $\Delta T_{1}$ & $\Delta T_{2}$ & $\Delta\left(\right.$ Dst $_{\text {peak }}-$ Dst $\left._{\text {peak }}^{*}\right)$ \\
\hline All Storm & 89 & $-160.2 \pm 74.5$ & $-18.34 \pm 10.31$ & $2.25 \pm 2.25$ & $4.27 \pm 3.51$ & $7.39 \pm 9.25$ \\
$-200 \mathrm{nT}<$ Dst $\leq-100 \mathrm{nT}$ & 71 & $-128.4 \pm 24.8$ & $-14.35 \pm 4.00$ & $2.37 \pm 2.33$ & $4.23 \pm 3.78$ & $5.46 \pm 7.78$ \\
$-300 \mathrm{nT}<$ Dst $\leq-200 \mathrm{nT}$ & 12 & $-243.8 \pm 35.1$ & $-30.87 \pm 12.05$ & $1.42 \pm 1.98$ & $3.83 \pm 2.29$ & $15.64 \pm 10.56$ \\
Dst $\leq-300 \mathrm{nT}$ & 6 & $-369.8 \pm 40.5$ & $-40.58 \pm 10.95$ & $2.5 \pm 1.38$ & $5.67 \pm 2.25$ & $18.5 \pm 8.96$ \\
\hline
\end{tabular}

Figure 6 shows the distribution of the storm number as a function of the delay $\Delta T_{1}$ between the $\mathrm{Bz}$ and Dst peaks. Fifty-two storms $(58.4 \%)$ had a delay of $0-2$ hours. Four storms (less than 5\%) had a negative delay between the $\mathrm{Bz}$ and Dst peaks; i.e., the Dst peak occurred before the $\mathrm{Bz}$ peak.
Figure 7 shows the distribution of the storm number as a function of the duration $\Delta T_{2}$ that $\mathrm{Bz} \leq-10 \mathrm{nT}$. It is seen that $\Delta T_{2}$ was between one and four hours for $48(53.9 \%)$ great storms. There were $11(12.4 \%)$ great storms with $\Delta T_{2}=0$, which means that the peak value of $\mathrm{Bz}$ did not reach $-10 \mathrm{nT}$ for these storms. The Dst 


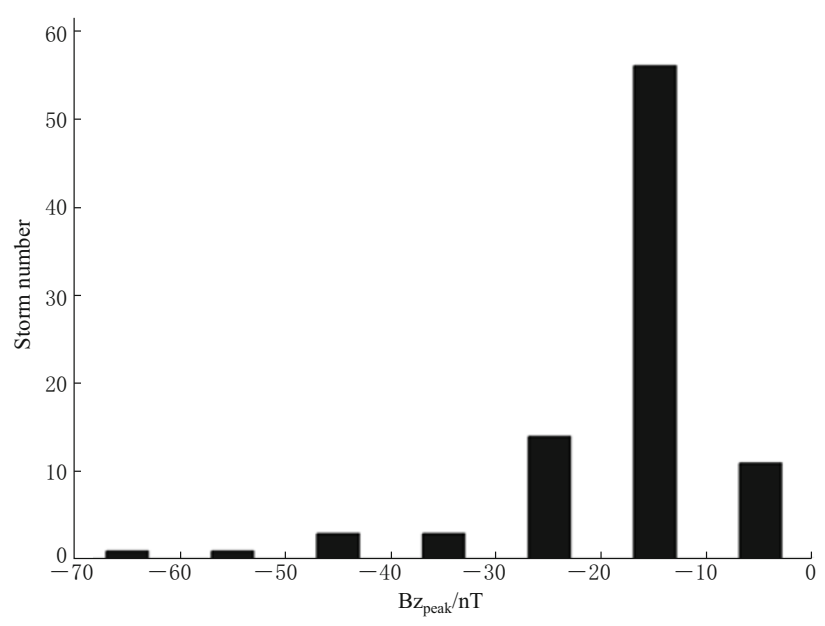

Figure 5 Distribution of the storm number as a function of the $\mathrm{Bz}$ peak for 89 great storms from 1996 to 2008 .

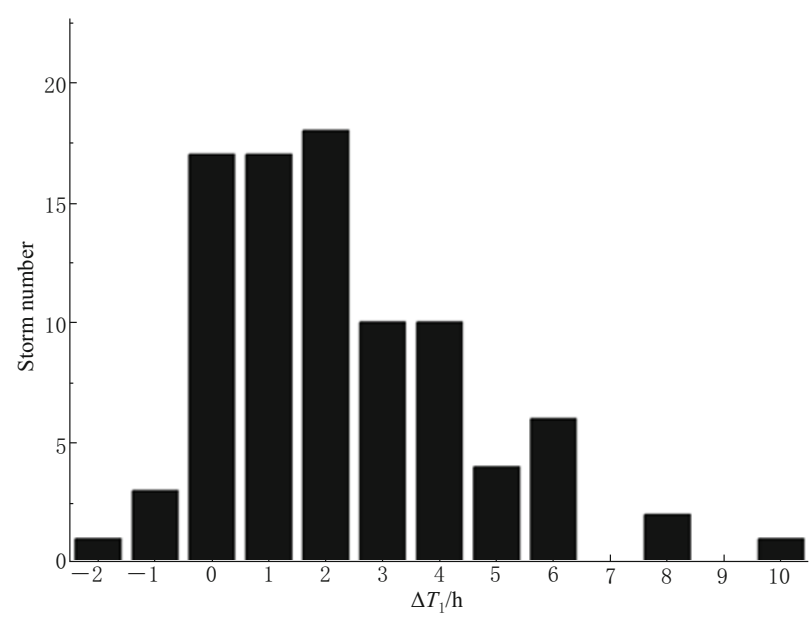

Figure 6 Distribution of the storm number as a function of the delay $\Delta T_{1}$ between the $\mathrm{Bz}$ and Dst peaks for 89 great storms from 1996 to 2008 (corrected by 1 hour).

peak values were larger than $-120 \mathrm{nT}$ for nine of these storms (with $\Delta T_{2}=0$ ), and the Dst peak values for the other two storms were -136 and $-148 \mathrm{nT}$. The maximum of $\Delta T_{2}$ was 16 hours for the storm starting on November 13, 1998, for which Dst peak $=-131 \mathrm{nT}$.

Figure 8 shows the correlation of the Dst peak and the $\mathrm{Bz}$ peak for the 89 storms studied. The formula for the least squares line is

$$
\text { Dst }_{\text {peak }}=-53.15+5.84 \times \mathrm{Bz}_{\text {peak }} .
$$

The correlation coefficient is 0.81 , which means that there was a relationship between the Dst peak and the $\mathrm{Bz}$ peak. However, the $\mathrm{Bz}$ peaks did not align with the fitting line when Dst was very high.

Figure 9 is a plot of the difference value $\Delta\left(\right.$ Dst $_{\text {peak }}-$ Dst $\left._{\text {peak }}^{*}\right)$ versus peak Dst. There were 50

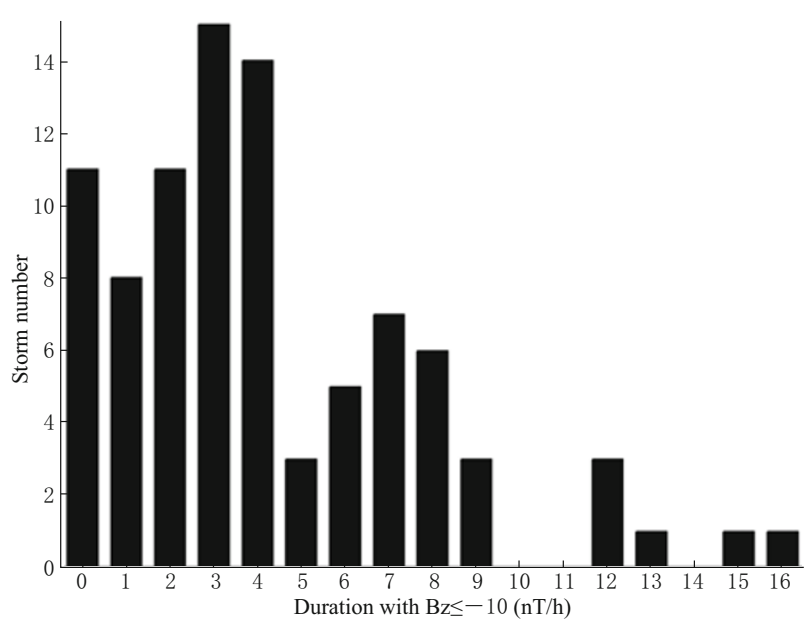

Figure 7 Distribution of the duration with $\mathrm{Bz} \leq-10 \mathrm{nT}$ for 89 great storms from 1996 to 2008 .

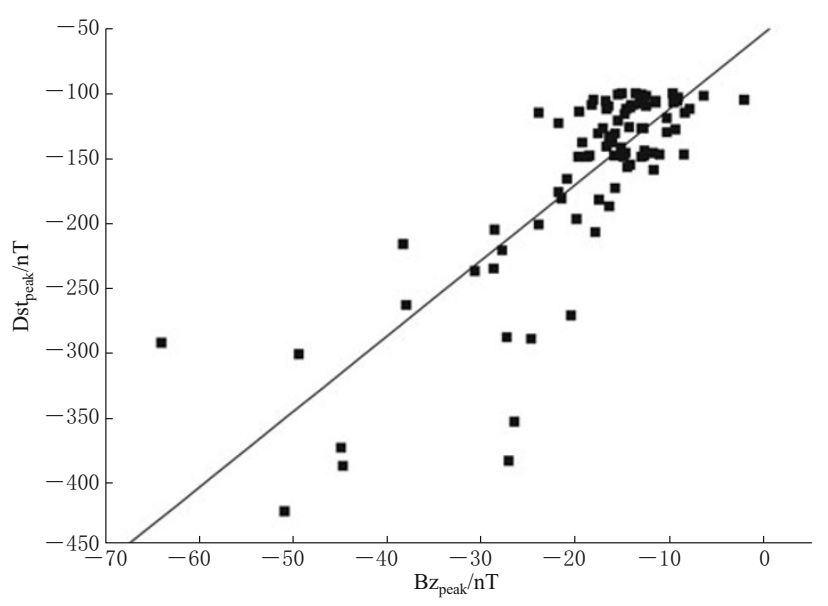

Figure 8 Correlation of the Dst peak and Bz peak for the 89 storms studied.

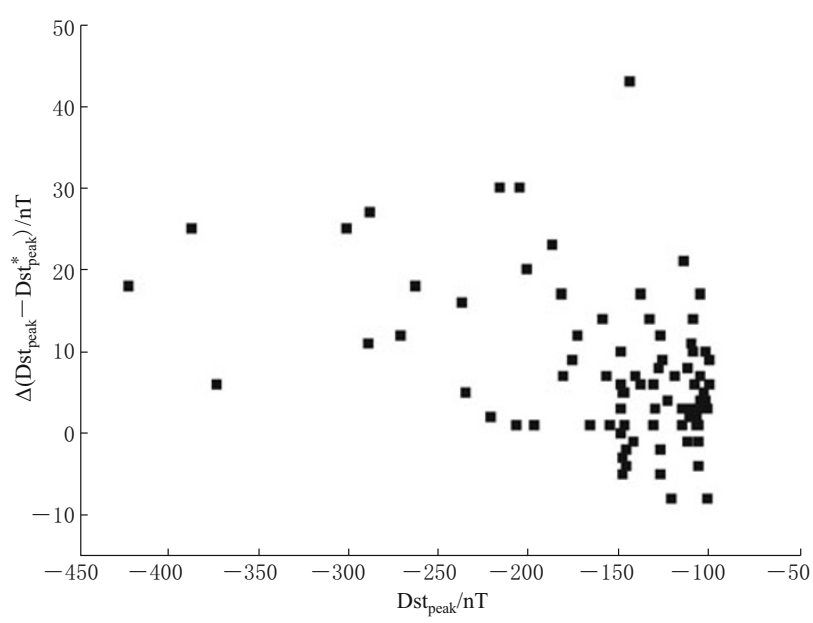

Figure 9 Correlation of the Dst peak and difference $\Delta\left(\right.$ Dst $_{\text {peak }}-$ Dst $\left._{\text {peak }}^{*}\right)$ between the Dst peak and the corrected Dst peak for 89 great storms from 1996 to 2008 . 
storms $\left(56.2 \%\right.$ of all studied) with $0 \mathrm{nT} \leq \Delta$ ( Dst $_{\text {peak }}-$ Dst $\left._{\text {peak }}^{*}\right) \leq 10 \mathrm{nT}$. There were 12 storms with $\Delta\left(\right.$ Dst peak $_{\text {pe }}$ Dst $\left._{\text {peak }}^{*}\right)<0$. The correlation coefficient is -0.445 .

Figure 10 shows the correlation of Dst $_{\text {peak }}^{*}$ and $\mathrm{Bz}_{\text {peak }}$. The formula for the least squares line is

$$
\mathrm{Dst}_{\text {peak }}^{*}=-42.55+6.75 \times \mathrm{Bz}_{\text {peak }} .
$$

The correlation coefficient is 0.86 . Hence, the correlation coefficient is higher than that for the relationship between Dst $_{\text {peak }}$ and $\mathrm{Bz}_{\text {peak }}$, and the $\mathrm{Bz}$ peaks align with the fitting line.

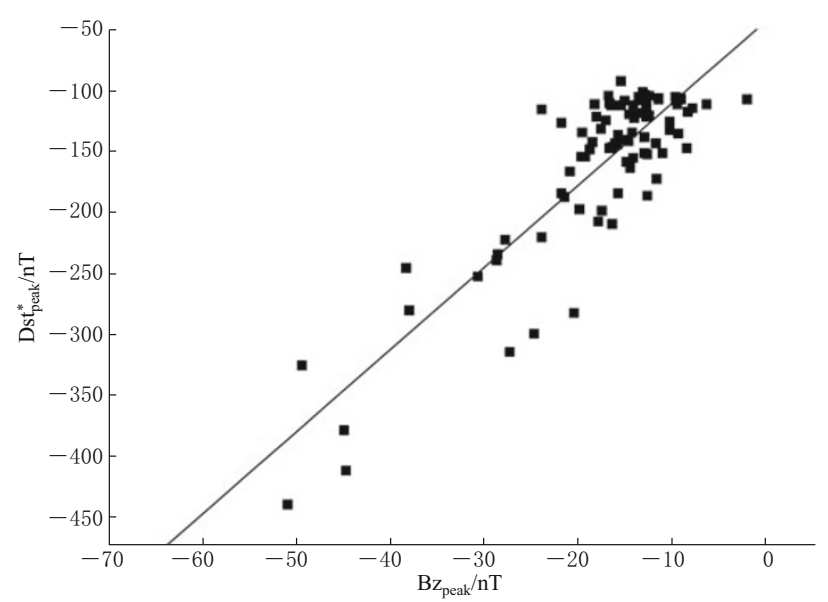

Figure 10 Correlation of the corrected Dst peak and the $\mathrm{Bz}$ peak for 89 great storms from 1996 to 2008.

\section{Discussion and conclusions}

Comparing solar cycle 23 with other solar cycles, it was found that the ratio of the storm number to the maximum annual number of sunspots is greatest in cycle 23 for storms with Dst $\leq-100 \mathrm{nT}$ or Dst $\leq-200 \mathrm{nT}$. Considering the low number of sunspots, the magnetic activity of solar cycle 23 appears severe.

Figure 3 shows that there was a close relationship between the sunspot number and great storm number in the period from 1957 to 2008 . The contribution of the sunspot number is still consistent with that of the great storms with Dst $\leq-100 \mathrm{nT}$. We can conclude from Figure 2 that the relationship between the sunspot number and the great storm number weakened as the activity of the storms strengthened. There was no obvious relationship between the annual sunspot number and great storm number with Dst $\leq-300$ nT. Echer et al. (2011) studied 1377 geomagnetic storms with peak Dst $\leq 50 \mathrm{nT}$ for the period from 1957 to 2008, and indicated that less intense storms have their peak occurrences in the declining phase, while more intense storms tend to have higher occurrence rates near solar maximum. Gonzalez et al. (2011b) studied the distribution of superintense (Dst $\leq-250 \mathrm{nT}$ ) storms during the space era, and pointed out that superstorms occurred during all phases of the solar cycle, although with a higher tendency around solar maximum and at the early descending phase of the cycle. Thus, for storm-forecasting purposes, it is hard to predict the great storm with Dst $\leq-300 \mathrm{nT}$ based on the expected sunspot number or the phase of the solar cycle.

The Bz peak had an average magnitude of -18.15 $\mathrm{nT}$, and $87.6 \%$ of studied great storms had $\mathrm{Bz} \leq-10$ $\mathrm{nT}$. The peak value of $\mathrm{Bz}$ did not reach $-10 \mathrm{nT}$ for 11 studied storms, and the Dst peak values for these storms were larger than $-150 \mathrm{nT}$. It was found that the condition $\mathrm{Bz} \leq-10 \mathrm{nT}$ was not necessary for storms with Dst $\leq-100 \mathrm{nT}$, but seems necessary for storms with Dst $\leq-150 \mathrm{nT}$. Bz $\leq-10 \mathrm{nT}$ can be regarded as the threshold of causing strong storms with Dst $\leq-150$ $\mathrm{nT}$. Of course, more examples are needed to prove it.

The maximum duration with $\mathrm{Bz} \leq-10 \mathrm{nT}$ was 16 hours for the storm that started on November 13, 1998, and the Dst peak for this storm was $-131 \mathrm{nT}$. It is found that the duration with $\mathrm{Bz} \leq-10 \mathrm{nT}$ is not in proportion to the strength of a storm.

The average delay time between the Dst and $\mathrm{Bz}$ peaks was 2.25 hours. For different groups of storm sorted by the storm activity, the average delay time did not vary too much. The maximum delay was 10 hours. The result is similar to that of Gonzalez and Echer (2005), which was derived from 64 intense geomagnetic storms (Dst $\leq 85 \mathrm{nT}$ ) from 1997 to 2002. 58.4\% of the studied storms had a delay of 0-2 hours. Four storms had a negative delay between the $\mathrm{Bz}$ and Dst peaks. The delay time may suggest a physical response time of the ring current to the solar wind driver at the peak interval of an intense magnetic storm, and could be applied to model the ring current dynamics and studies of loss processes near the peak of the storm.

There was a close relationship between the Dst peak and Bz peak for the 89 storms studied, with the correlation coefficient being 0.81 . After removing the effect of solar wind dynamic pressure on the Dst peak, we obtained a better correlation coefficient of 0.86. During geomagnetic storms, Bz plays an important role in energyt ransfer from the solar wind to the magnetosphere and Dst are usually used as measurment of the westward ring current. Above result suggest that Dst are closer to the energy of ring current after removing the 
effect of solar wind dynamic pressure.

We believe that these results are of practical importance for spaceweather applications.

Acknowledgements This research was supported by the project Environment Building for S\&T Industries (2005DKA64000). The Dst index and sunspot numbers were downloaded from the websites http://swdcwww.kugi.kyoto-u.ac.jp/index.html and http://www.ngdc.noaa.gov/stp/ respectively. The interplanetary parameters were downloaded from http://omniweb.gsfc.nasa.gov/.

\section{References}

Akasofu S-I (1981). Energy coupling between the solar wind and the magnetosphere. Space Sci Rev 28: 121-190.

Burton R K, Burton R K, Mcpherron R L and Russel C T (1975). An empirical relationship between interplanetary conditions and Dst. J Geophys Res 80(31): 4 204-4 214.

Chapman S and Bartels J (1940). Geomagnetism. Clarendon Press, Oxford, 355-395.

Dal Lago A, Vieira L E A, Echer E, Gozales W D, Clua de Gonzalez A L, Guarnieri F L, Balmaceda L, Santos J, da Silva M R, de Lucas A and Schuch N J.(2004). Great geomagnetic storms in the rise and maximum of solar cycle 23. Brazilian Joural of Physics 34: 1 542-1 546.

Dungey J W (1961). Interplanetary magnetic field and auroral zones. Phys Rev Lett 6: 47-48.

Echer E, Gonzalez W D and Tsurutani B T (2008a). Interplanetary conditions leading to superintense geomagnetic storms (Dst $\leq-250 \mathrm{nT}$ ) during solar cycle 23. Geophys Res Lett 35: L06S03, doi:10.1029/2007GL031755.

Echer E, Gonzalez W D, Tsurutani B T and Gonzalez A L C. (2008b). Interplanetary conditions causing intense geomagnetic storms (Dst $\leq-100 \mathrm{nT})$ ) during solar cycle 23 (1996-2006). J Geophys Res 113: A05221, doi:10.1029/2007JA012744.

Echer E,Gonzalez W D, Tsurutani B T (2011). Statistical studies of geomagnetic storms with peak Dst $\leq-50 \mathrm{nT}$ from 1957 to 2008. Journal of Atmospheric and SolarTerrestrial Physics 73: 1 454-1 459.

Gonzalez W D and Tsurutani B T (1987). Criteria of interplanetary parameters causing intense magnetic storms (Dst $\leq 100$ nT). Planet Space Sci 35: 1 101-1 109.

Gonzalez W D, Tsurutani B T, Gonzalez A L C, Smith E J, Tang F and Akasofu S-I (1989). Solar windmagnetosphere coupling during intense magnetic storms (1978-1979). J Geophys Res 94 (A7): 8 835-8 851.

Gonsalez W D and Echer E (2005). A study on the peak Dst and peak negative $\mathrm{Bz}$ relationship during intense geomagnetic storms. Geophys Res Lett 32: L18103,
doi:10.1029/2005GL023486.

Gonzalez W D, Echer E, Clua-Gonzalez A L and Tsurutani B T (2007). Interplanetary origin of intense geomagnetic storms (Dst $\leq 100 \mathrm{nT}$ ) during solar cycle 23. Geophys Res Lett 34: L06101, doi:10.1029/2006GL028879.

Gonzalez W D, Joselyn J A, Kamide Y K, Kroehl H W, Rostoker G, Tsurutani B T and Vasyliunas V M (1994). What is a geomagnetic storm? J Geophys Res 99(A4): $5771-5792$.

Gonzalez W D, Echer E, Tsurutani B T, Clua-Gonzalez A L, Alisson Dal Lago (2011a). Interplanetary origin of intense, superintense and extreme geomagnetic storms. $S$ pace Science Reviews 158: 69-89.

Gonzalez W D, Echer E, Clua-Gonzalez A L, Tsurutani B T and Lakhina G S (2011b). Extreme geomagnetic storm$\mathrm{s}$, recent Gleissberg cycles and space era-superintense storms. Journal of Atmospheric and Solar-Terrestrial Physics 73: 1 447-1 453.

Gopalswamy N, Yashiro S, Michalek G, Xie H, Lepping R P and Howard R A (2005). Solar source of the largest geomagnetic storm of cycle 23. Geophys Res Lett 32: L12S09, doi:10.1029/2004GL021639.

Kane R P and Echer E (2007). Phase shift (time) between storm-time maximum negative excursions of geomagnetic disturbance index Dst and interplanetary Bz. Journal of Atmospheric and Solar-Terrestrial Physics 69: 1 0091020 .

Perreault P and Akasofu S-I (1978). A study of geomagnetic storms. Geophys J 54: 547-573.

Russell C T, McPherron R L and Burton R K (1974). On the cause of geomagnetic storms. J Geophys Res 79: 1 105-1 109.

Tsurutani B T and Gonzalez W D (1997). The interplanetary causes of magnetic storms: A review in magnetic storms. Tsurutani B T, Tsurutani B T, Gonzalez W D, Kamide Y and Arballo J K eds. Geophys Monogr Ser $A G U$, Washing, D. C., 98: 77-89.

Turner N E, Baker D N, Pulkkinen T I, Roeder J L, Fennell J F and Jordanova V K (2001). Energy content in the storm time ring current. J Geophys Res 106(A9): 19 149-19 156.

Zhang J, Richardson I G., Webb D F, Gopalswamy N, Huttunen E, Kasper J C, Nitta N V, Poomvises W, Thompson B J, Wu C-C, Yashiro S and Zhukov A N (2007). Solar and interplanetary of major geomagnetic storms (Dst $\leq 100 \mathrm{nT}$ ) during 1996-2005 J Geophys Res 112: A10102, doi:10.1029/2007JA12321.

Zhang Y, Le G M and Liu L G (2011). Analysis of the interplanetary sources for the main phase of the geomagnetic storm during October 18-19, 1998. Chinese J Space Sci 31(3): 294-298. 